\title{
Observation of spore germination in Physarum globuliferum
}

\author{
Lv Dong Xia, Wang Xiao Li, Li Chen, Wang Xiao Li and Li Yu
}

Engineering Research Center of the Chinese Ministry of Education for Edible and Medicinal Fungi, Jilin Agricultural University, Changchun 130118, China.

Accepted 10 May, 2013

\begin{abstract}
We described in detail the spore germination events in Physarum globuliferum. Observations were made using depression slides under a computer-supported video microscope. When a spore germinated, one protoplast, one myxamoeba or one swarm cell emerged; not more than one of these was observed. Under most conditions, the release of the spore protoplast was accomplished by the splitting of the spore wall into what appeared to be a V-shaped opening. Sometimes, the spores germinated through a minute pore dissolved in the spore wall and a myxamoeba or a swarm cell emerges. Under unfavorable conditions, myxamoeba may round up to form microcysts. Swarm cells are peanut-like, with one anteriorly attached flagellum. The pseudopodium of the myxamoeba is a typical lobopodium containing endoplasm only.
\end{abstract}

Key words: Myxomycete, protoplast, swarm cell, myxamoeba, microcyst.

\section{INTRODUCTION}

Although there have been numerous relevant studies, the detailed life cycle events are known for few myxomycetes, even for those in the order Physarales. The first report of germination of spores in myxomycetes was made by deBary (1854). The first spore-to-spore cultures of myxomycetes were reported by Lister (1901). Recent research shows that the products that emerge from the germinating spores include protoplasts, swarm cells and myxamoeba, formed from splits or pores. The number of products from a single spore was considered to be one, two, or even more. Elljott (1949) reported that germination was obtained in 80 of 90 collections, and that most produced swarm cells. Germination of spores of Physarum gyrosum occurred by splitting, and the addition of cellulose resulted in the emergence of a protoplast through a pore rather than a split. Emergence of more than one protoplast from a spore was not observed (Koevenig, 1964). Gilbert (1928) and Smith (1929) both reported that approximately half the species they observed produced more than one swarm cell per spore. Spores of Physarum spinisporum germinated via a wedge-shaped split (Keller and Schokntcht, 1989a). Spores of Didymium annulisporum germinated by splitting, and development of flagella sometimes occurred while the protoplast was in the spore case (Keller and Schokntcht, 1989b). Germination was by a V-shaped split in the spore wall of Didymium umbilicatum, and myxamoebae were produced (de Basanta et al., 2008). Germination was by a V-shaped split in the spore wall of Didymium wildpretii, and the products included swarm cells and myxamoebae (Lado et al., 2007). Thus, the early workers, who made valiant attempts to germinate myxomycete spores, met with varying success. Microcysts are resistant structures formed by myxamoebae, enabling myxomycetes to survive unfavorable environmental conditions (Raub and Aldrich, 1982).

Our experiment provides evidence that the germination 


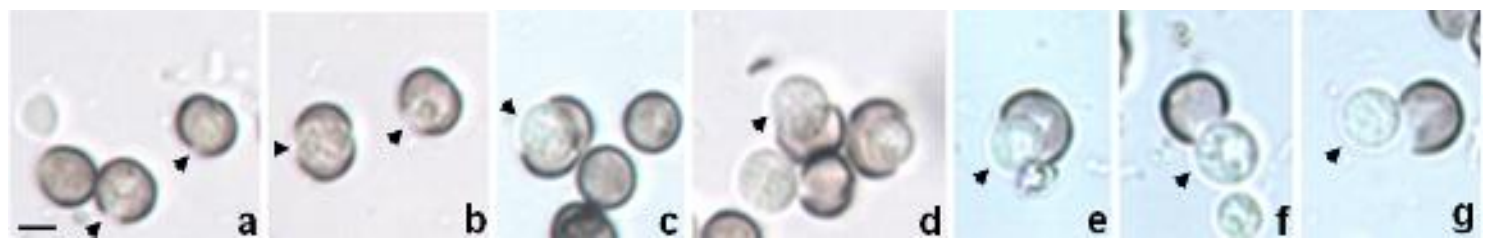

Figure 1. A protoplast emerging from a germinating spore. Arrows in a and b show structural weakness in the spore wall, that is, the future germination site. Arrows in $\mathrm{c}$ to $\mathrm{g}$ show a protoplast which appears to have been the full contents of the spore. Scale bar $=6 \mu \mathrm{m}$.

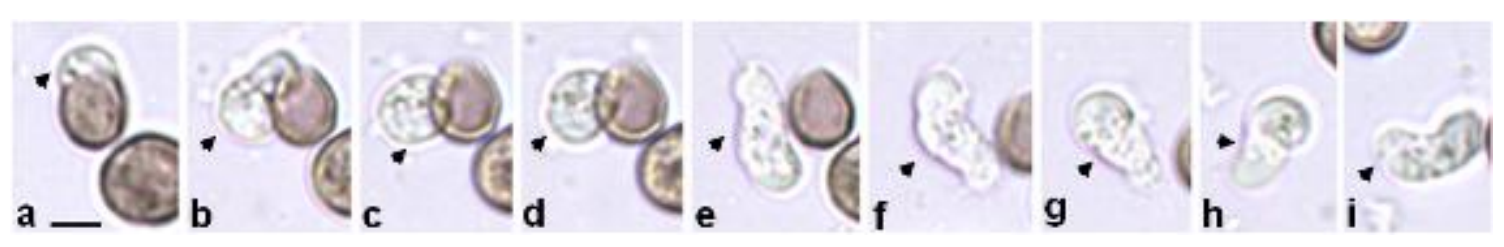

Figure 2. A swarm cell escaping from a germinating spore. Arrows in a to d indicate protoplasm, e to $i$ indicate the swarm cell, with the anterior uniflagellum visible at the time of emergence. Variation in the shape of the swarm cell is due to cell movement. Scale bar $=4 \mu \mathrm{m}$.

pattern of the fresh spores of Physarum globuliferum is influenced only by water or moisture. Microcysts are formed by myxamoebae under drought conditions. $P$. globuliferum (Bull.) Pers. is a common myxomycete species. Its cultivation method, mating types (Gray and Alexopoulos, 1968; Henney, 1968), phaneroplasmodium (Alexpoulos, 1969) and mature sporocarps (Martin and Alexopoulos, 1969) were described during the 1960s. Recently, Liu et al. (2010) reported that spore germination began via a minute pore, and that myxamoebae released from spores sometimes developed into swarm cells with flagella, spore to spore was accomplished. Main process of life cycle was on the sporulation. We focused on the spore germination event in $P$. globuliferum, and included clear micrographs of relevant details.

\section{MATERIALS AND METHODS}

Specimens were collected from Changbai Mountain, Jilin Province, China. Collections were identified as $P$. globuliferum based on morphology, including spores, capillitia and columellae. They were deposited in the Mycological Herbarium of Jilin Agricultural University (HMJAU).

\section{Subculturing}

Fresh spores for observation of germination were obtained from spore-to-spore cultures. The plasmodium was maintained on WA (water agar) and fed with oat-flakes and sterile water for long-term maintenance.

\section{Hanging drop cultures}

Hanging drop cultures were prepared for observation of spore germination. Fresh spores were mixed in a droplet of sterile water on a depression slide over which a cover glass was placed. Vaseline was used to ring the edges of the cover glass.

\section{Agar cultures}

Cultures were also prepared on agar for observation of spore germination. Fresh sporocarps were crushed and spread onto the $0.75 \%$ water agar in sterile $9 \mathrm{~cm}$ plastic Petri dishes at $\mathrm{pH} \mathrm{7.0.} \mathrm{All}$ cultures were kept in the dark at temperatures of 22 to $25^{\circ} \mathrm{C}$. Microscopic measurements and observations were made using lenovo computer-supported video microscopy (Nikon 80i) with Cooled Camera Head (DS-Ri1). The software, NIS-Elements D was used.

\section{RESULTS}

Germination of fresh spores occurred within 3 and $4 \mathrm{~h}$. An empty spore wall remained after emergence of the protoplast or other forms. Single spores gave rise to only one protoplast, one swarm cell, or one myxamoeba (Figures 1, 2 and 3). In no culture was emergence of more than one protoplast or other form observed from a single spore. Under most conditions, the release of the spore protoplast was accomplished by the splitting of the spore wall to form what appeared to be a V-shaped opening (Figure 1a to g), especially if the spores were on agar. Protoplasts increased in size and actively moved before spore germination. Over the next 3 to $4 \mathrm{~h}$, the split widened laterally and at the same time the protoplast increased in size, forcing the spore to gape open (Figure $1 \mathrm{a}$ and b). Protoplasts were colorless, and lacked internal protoplasmic movements. The protoplasts seen were the full contents of the spore (Figure $1 \mathrm{c}$ to e). The protoplasts 


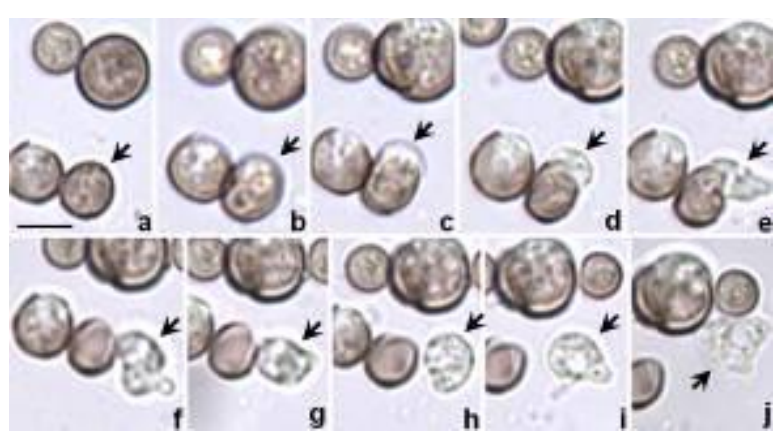

Figure 3. A myxamoeba flowing from a germinating spore. The arrow in a indicates the future site where the myxamoeba will emerge. Arrows in $b$ to $j$ indicate the myxamoeba. Scale bar $=8 \mu \mathrm{m}$.

from spores remain protoplast for a long time until they were moved to fresh agar covering a film of water, which were transformed to swarm cell. Spores of $P$. globuliferum usually germinated in the middle of the depression slide, and swarm cells emerged (Figure 2a to i). Anteriorly attached uniflagella were distinguishable under the light microscope. The emerging cells were often flagellate from the beginning. The growth of the flagellum either took place rather quickly, or the flagellum was formed within the spores. As a swarm cell escaped from the spore case, it increased in size and swam about immediately with a rapid rotary movement combined with amoeboid contractions (Figure $2 \mathrm{e}$ to $\mathrm{i}$ ). In our hanging drop cultures, swarm cells were active swimmers but settled down at the concave edges of depression slides. Swarm cells were typically peanut-shaped, bearing one flagellum located at the pointed anterior end.

The flagellum was directed anteriorly from the direction of forward movement. $P$. globuliferum swarm cells ranged from 15 to $20 \mu \mathrm{m}$ in length and 3 to $8 \mu \mathrm{m}$ in width. Eventually, the myxamoeba was seen flowing from the spore aperture (Figure $3 a$ to j). Spore contents usually bulged out of the opening, suggesting that internal pressure was forcing out the amoeba (Figure $3 b$ to $d$ ). Emergence of a swarm cell or amoeba was through a pore rather than a split. More myxamoebae were found around the upper parts of the concave surface of the depression slide, while more swarm cells were observed in the lower parts of the depression. Myxamoebae from liquid cultures were characterized by the presence of pseudopodia and several apparently empty vacuoles in their cytoplasm. Myxamoebae were variable in the form of their amoeboid movement, their size varied little, and they were about 15 to $20 \mu \mathrm{m}$ in diameter. Myxamoebae crawled about by means of pseudopodia, typically in the form of lobopodia, and resembling those of Amoeba proteus. The pseudopodia had a distinct obtuse-round leading edge, and were without translucent ectoplasm. One prominent contractile vacuole in the rounded posterior end was observed clearly during crawling.
Some myxamoebae at upper levels of the depression slide began to retract pseudopodia and differentiate into microcysts if there was no constant supply of supplementary water (Figure $4 a$ to $d$ ). Drought is thus a reason for the transformation to encystment.

\section{DISCUSSION}

The appropriate requirement of spore germination was in neutral or slightly acid media, at temperatures near $25^{\circ} \mathrm{C}$ (Elljott, 1949; Liu et al., 2010). More myxamoebae would emerge from spore at upper limit of tolerance temperature (Elljott, 1949). But not more evidence showed this later. Repeated drying and rewetting of culture facilitated the spore germination. Darkness was needed before sporulation and illumination was a requirement for the $P$. globuliferum phaneroplasmodium for sporulation (Liu et al., 2010). Lado et al. (2007) found that on the drier $1.5 \% \mathrm{WA}$, most of the swarm cells reverted to myxamoebae which was on the $0.75 \%$ WA initially. This is identical with our observation. Of all the physical factors in the environment normally encountered in laboratory procedures, wetness of the substrate was found to be the most significant for spore germination. The patterns of spore germination were generated by the transit of the self-organized spore responding to surrounding moisture, while other factors were optimal. We showed a pattern of multiformity in spore germination within same myxomycete species. Protoplasts, swarm cells, or myxamoebae were observed simultaneously from different spores of $P$. globuliferum. Spores at the upper levels of the depression slide or on agar produced myxamoebae or protoplasts. In contrast, spores at lower locations readily produced swarm cells. The only different physical factor between these spores on same depression slide was wetness.

Most attempts at the spore germination of myxomycetes have produced swarm cells, this does not imply that the spore readily produces swarm cells, in fact, all previous researchers have realized the importance of wetness for germination, and made available sufficient water. The spore of $P$. globuliferum germination began by the appearance of a minute pore dissolved in the spore wall and a myxamoeba released from spores was observed by Liu et al. (2010), and complete life cycle was accomplished. But other possible situation of spore germination has not been observed and discussed in her work. The several kinds of products from spore germination have been reported before, and we also observed them. This indicates that any results may be observed under favorable conditions. More than one product from a single spore was not observed in our cultures. These results agree with those of Elljott (1949), despite reports that more than one, even four products, were observed from single spores (Gilbert, 1928; Smith, 1929). The reason for this may be lack of sufficient nutrient to induce division of the protoplasm in spores, or 


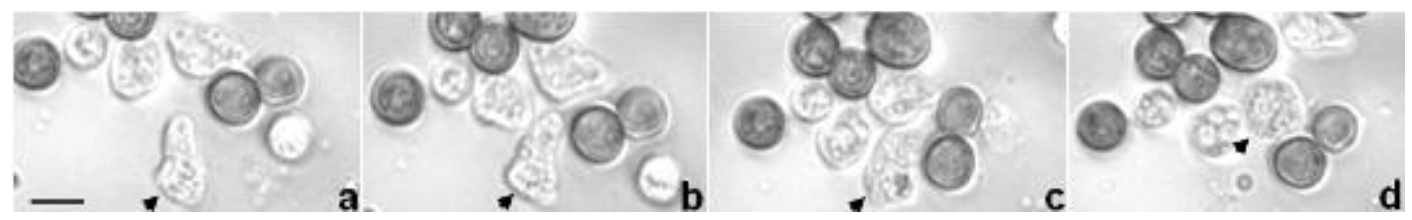

Figure 4. Myxamoeba rounding to encyst under drought conditions. Arrows in a to $\mathrm{c}$ indicate the product from the spore. The arrow in d indicates the microcyst. Scale bar $=9 \mu \mathrm{m}$.

a problem within a particular species.

Germination always develops within the smooth area on the spore surface. This area appears paler and thinner under a light microscope and marks the future site where the product (protoplast, or swarm cell, or myxamoeba) emerges. Spore germination sites were never observed to develop within the spiny spore surface area which appears darker and thicker-walled under the light microscope. This agrees with observations by Keller and Schoknecht (1989a). In Physarum compressum the surface ornamentation of spores that has been observed, develop with spore wall during sporulation ( $\mathrm{Li}$ et al., 2011). These ornamentations intensified the thickness of the spore wall, thus suggesting a reasonable explanation for the above observations. The structural weakness in the spore wall represents the future site of spore germination in $P$. globuliferum. Germination occurring by the splitting method is similar to that described by Keller and Schokntch (1989a, b). The size of the split appears to depend upon the age of the spores (older spores develop a smaller split), and also on environmental conditions (Koevenig, 1964). The fresh spores of $P$. globuliferum exhibited larger splits in our culture. A swarm cell or myxamoeba emerged through a pore rather than a split.

Biflagellation has been frequently reported in myxomycetes, although in our cultures, only one anterior flagellum was clearly observed under the light microscope. Two basal bodies in the cytoplasm beneath the flagellum have been considered evidence for the presence of two (Haskins and Mcguinness, 1988). Perhaps most swarm cells are potentially biflagellate, but the second flagellum is difficult to see under the light microscope. The myxamoeba of $P$. globuliferum do not have translucent ectoplasm, similar to the myxomycete of Didymium umbilicatum (de Basanta et al., 2008).

We did observe the microcysts mentioned by Lado (2007). Amoebae from spores may begin to retract pseudopodia and differentiate into microcysts under unfavourable environmental conditions. It is the amoebae rather than the swarm cells which are able to withdraw their flagella when they encounter adverse conditions. Koevenig (1964) reported that cell division occurs only in myxamoebae, since the dividing cell reabsorbs its flagellum before or during prophase; where a swarm cell refers to a flagellated cell and a myxamoeba to a nonflagellate cell. Whether these biological events occur in myxamoebae or swarm cells appears to be a semantic problem only. Myxamoebae can easily be distinguished from swarm cells by their distinct shape.

\section{ACKNOWLEDGEMENTS}

This work was supported by the National Natural Science Foundation of China (Project No. 31070011), and the Natural Science Foundation of Jilin Province (Project No. 201115190).

\section{REFERENCES}

Alexopoulos CJ (1969). The experimental approach to the taxonomy of the myxomycetes. Mycologia 61:219-239.

deBary A (1854). Euglenartige gebilde aus sporen von Trichia rubiformis. Flora 12:648.

de Basanta DW, Lado C, Estrada-Torres A (2008). Morphology and life cycle of a new species of Didymium (Myxomycetes) from arid areas of Mexico. Mycologia 100(6):921-929.

Elljott EW (1949). The swarm-cells of myxomycetes. Mycologia. 41(2):141-170.

Gilbert FA (1928). A study of the method of spore germination in myxomycetes. Am. J. Bot. 15:345-352.

Gray WD, Alexopoulos CJ (1968). Biology of myxomycetes. The Ronald Press Company, New York. pp. 1-89.

Haskins EF, Mcguinness MD (1988). Ultrastructure of the flagellar apparatus of the slime mold Semimorula liquescens. Mycologia 80(5):630-635.

Henney MR (1968). Mating type systems in myxomycetes Physarum globuliferum and Physarum bilgramii. Am. J. Bot. 55:720.

Keller HW, Schokntcht JD (1989a). Spore-to-spore culture of Physarum spinisporum and its transfer to Badhamia. Mycologia 81(4):631-636.

Keller HW, Schoknecht JD (1989b). Life cycle of a new annulate-spored species of Didymium. Mycologia 81(2):248-265.

Koevenig JL (1964). Studies on life cycle of Physarum gyrosum and other myxomycetes. Mycologia 56(2):170-184.

Lado C, Mosquera J, Beltrán-Tejera E, de Basanta DW (2007). Description and culture of a new succulenticolous Didymium (Myxomycetes). Mycologia 99(4):602-611.

Li YS, Yu L, Wang XL, Li Y (2011). Ultrastructural studies on sporulation of Physarum compressum. Mycosystema 30(1):138-141.

Lister A (1901). On the cultivation of mycetoza from spores. J. Bot. 39:57-63.

Liu P, Wang Q, Li Y (2010). Spore-to-spore agar culture of the myxomycete Physarum globuliferum. Arch. Microbiol. 192:97-101.

Martin GW, Alexopoulos CJ (1969). The myxomycetes. University of lowa Press, lowa P. 279.

Raub TJ, Aldrich HC (1982). Sporangia, spherules and microcysts. In: Aldrich HC, Daniel JW (eds) Cell biology of Physarum and Didymium. Vol. II. New York, Academic Press, pp. 21-75.

Smith EC (1929). Some phases of spore germination of myxomycetes. Am. J. Bot. 16:645-650. 